\title{
SCINTIGRAPHIC EVALUATION OF KIENBOCK'S DISEASE IN COMPARISON TO PLAIN RADIOGRAPHY
}

\author{
Zaheer Chiragh ${ }^{l}$, Muhammad Iftikhar Alam ${ }^{l}$ \&. Shahab Fatmi ${ }^{1}$
}

1. Department of Nuclear Medicine, Bahawalpur Institute of Nuclear Medicine \& Oncology (BINO), Bahawalpur, Pakistan

Corresponding author: zc.dr@hotmail.com

\begin{abstract}
Kienbock's disease is a rare pathology of uncertain etiology, resulting in osteonecrosis of lunate bone. The authors present interesting images for comparison of both plain radiography and bone scan findings done in a young male laborer.
\end{abstract}

\section{KEY WORDS}

Kienbock's disease; bone scan; x-ray; lunate, osteo-necrosis, etiology, osteomalcia, palpable, tenderness, gout, cerebral palsy, sickle cell anemia tomography, Osteochondral

\section{INTRODUCTION}

It a disorder clinically evident at the wrist joint. It has been named after Dr. Robert Kienböck from Austria who for the first time described it as osteomalcia of the lunate in 1910 [Kienböck, 1910]. It is presumed to affect people of young age (15-40 years). Clinical manifestation may precede the radiological diagnosis \& symptoms mainly include recurrent pain, stiffness, and limitation of extension of wrist. Clinically palpable swelling may also be noted over lunate bone area associated with tenderness on palpation.

\section{CASE REPORT}

The authors present local bone scan and $\mathrm{x}$-ray images of 22 years old male, simple laborer by profession, who sustained a blunt trauma to the right hand about four years ago. He had been treated conservatively and current complaint was intermittent pain in the right hand that worsened on extension \& moderately alleviated with oral non-steroidal anti-inflammatory drugs (NSAIDs). Referring physician sent the patient to both the X-ray and nuclear medicine departments with a working diagnosis of Figures.

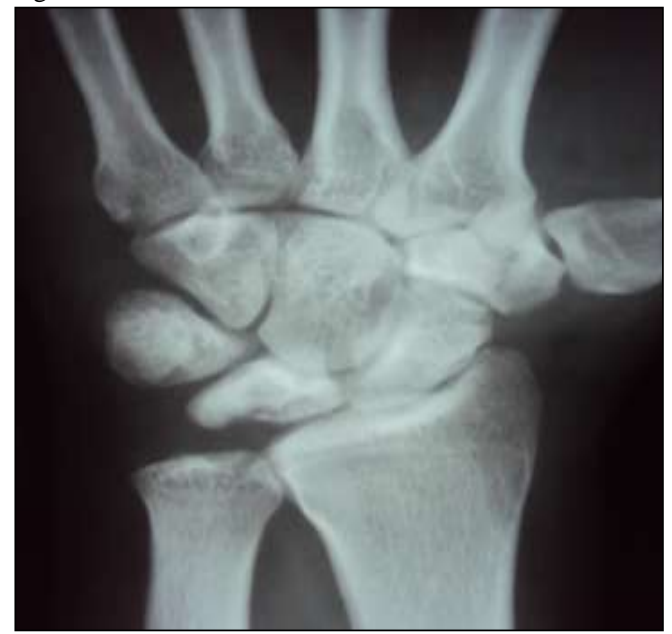

Figure 1. Plain radiograph of right hand showing sclerotic changes in lunate bone
Kienbock's disease (lunate bone)

The plain X-ray AP view of right hand that showed sclerotic changes of the lunate bone [Figure. 1]. Bone scan was performed

with Tc-99m Methylene diphosphonate (Tc-99m MDP), initial rapid flow \& pool phase were obtained in an anterior projection

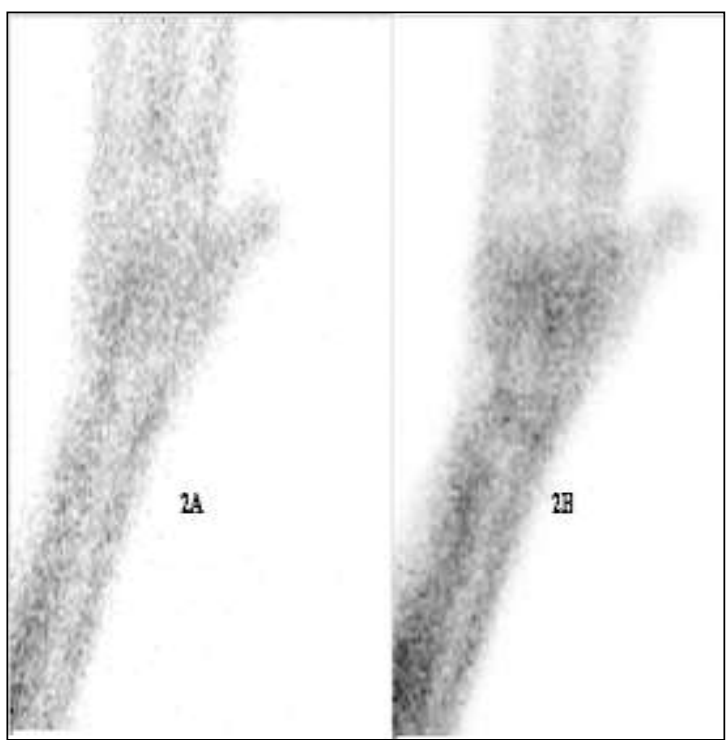

Figure. 2 A \& 2 B. The dynamic imagining did not depict any abnormal perfusion of pooling pattern.

Delayed static planar and pin-hole imaging showed abnormally increased focal uptake coinciding with the anatomical location of lunate bone [Figure $3 \mathrm{~A} \& 3 \mathrm{~B}$ ]. The scan was reported as positive focal bone pathology of lunate. 


\section{DISCUSSION}

Lunate osteomalacia is a peculiar lesion of the lunate or semilunar bone of the wrist resulting in necrosis. Radiographic findings are described as most widely accepted Lichtman's Radiographic Classification of Kienbock's Disease; Stage I-Normal radiograph, Stage II-Sclerosis of lunate with possible decrease of lunate height on radial side only, Stage IIIa-Lunate collapse, no scaphoid rotation, Stage IIIb-Lunate collapse, fixed scaphoid rotation, Stage IV-Degenerative changes around the lunate.

The patho-physiology of the disease mainly includes loss of blood supply to the lunate secondary to multiple probabilities as abnormal blood supply \& drainage system, skeletal variations i.e., shorter length of the ulna, any of the forearm bones $\&$ the shape of the lunate bone itself. Other possible factors that have also been postulated with reduced blood supply include local trauma, gout, cerebral palsy \& sickle cell anemia. Among the limited radionuclide imaging literature on the bone scan appearances of Kienbock's disease, Duong et al were the first to describe a case of Kienbock's disease with correlation of clinical, radiographic, scintigraphic, and pathologic findings [Duong, 1982]. Sowa et al have concluded that magnetic resonance.

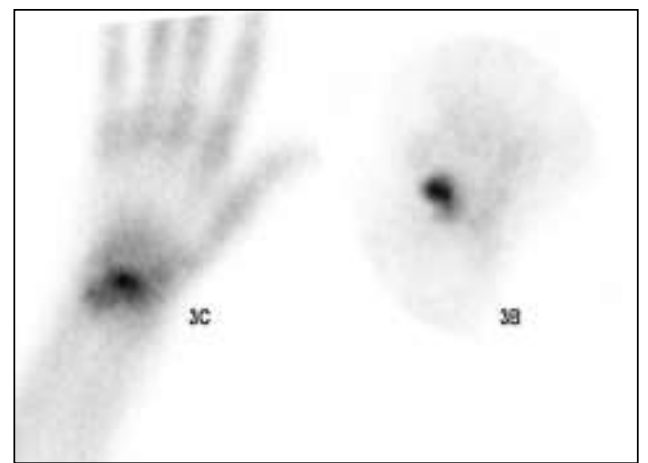

Figure 2 A \& 3 B. Delayed static \& pin hole bone scan images of right hand showing focal radiotracer uptake in the lunate bone imaging and scintigraphy have almost similar sensitivity but MRI having superior specificity [Sowa, 1989]. Amadio et al re Figure $3 \mathrm{~A} \& 2$ B. Initial flow (perfusion) and pool pahse of the bone scan.

Reported a case of false-negative imaging (e.g., plain radiographs, tomography, bone scan, and MRI) after 3 months of symptoms that was found positive for Kienbock's disease during review imaging at one year [Amadio, 1987]. The treatment options vary from case to case depending upon the severity of the disease and may range from simple conservative treatment to more complex surgical interventions. However, the main goal of the treatment is attempted towards restoring the blood supply to the lunate. Attempts have been made for the formation of neolunate by seeding scaffolds of hyaluronic acid and collagen were seeded with autologous stem cells in a rabbit model of Kienbock disease [Peter, 2005]. Future directions in treatment and research of the disease for appropriate management strategies are still a region of interest for researchers [Lichtman, 2010]. Pillukat et al have recommended arthroscopic evaluation to be conducted in addition to radiological parameters claiming that radiological evaluation can over- or under-estimate the articulating cartilage damage [Pillukat, 2010].
Osteochondral reconstruction has also shown promising results [Langer, 2010].

\section{REFERENCES}

- Kienböck, R. (1910): Über traumatische Malazie des Mondbeins und ihre Folgezustände: Entartungsformen und Kompressionfrakturen. Fortschritte auf dem Gebiete der Röntgenstrahlen. Über Luxationen im Bereich der Handwurzel.1910-1911;16:77-103. (LANGUAGE)

- Duong, R. B., Nishiyama, H., Mantil, J. C., Bever, J. D., Duong, S. L., \& Weinberg, S. (1982). Kienbock's Disease: Scintigraphic Demonstration in Correlation with Clinical, Radiographic, and Pathologic Findings: A Case Report. Clinical Nuclear Medicine, 7(9), 418-420

- Sowa, D. T., Holder, L. E., Patt, P. G., \& Weiland, A. J. (1989). Application of magnetic resonance imaging to ischemic necrosis of the lunate. The Journal of hand surgery, 14(6), 1008-1016

- $\quad$ Amadio, P. C., Hanssen, A. D., \& Berquist, T. H. (1987). The genesis of Kienböck's disease: evaluation of a case by magnetic resonance imaging. The Journal of hand surgery, 12(6), 1044-1049.

- Peter, C. (2005) Amadio: What's New in Hand Surgery. J Bone Joint Surg Am. (87)468-474.

- $\quad$ Lichtman, D. M., Lesley, N. E., \& Simmons, S. P. (2010). The classification and treatment of Kienböck's disease: the state of the art and a look at the future. Journal of Hand Surgery (European Volume), 35(7), 549-554.

- .Pillukat, T., Kalb, K., Schoonhoven, J. V., \& Prommersberger, K. J. (2010). The Value of Wrist Arthroscopy in Kienböck's Disease. Handchirurgie, Mikrochirurgie, plastische Chirurgie, 42(03), 204-211.

- $\quad$ Langer, M. F., Wieskötter, B., Vordemvenne, T., \& Surke, C. (2010). Osteochondral reconstruction of the lunate fossa in proximal row carpectomy for Kienböck's disease early stage IV]. Handchirurgie, Mikrochirurgie, plastische Chirurgie: Organ der Deutschsprachigen Arbeitsgemeinschaft für Handchirurgie: Organ der Deutschsprachigen Arbeitsgemeinschaft für Mikrochirurgie der Peripheren Nerven und Gefässe: Organ der Vereinigung der Deutschen Plastischen Chirurgen, 42(3), 2 